\title{
Contribution of Geographic Location to Disparities in Ovarian Cancer Treatment
}

\author{
Carolina Villanueva, MPH; Jenny Chang, MPH'; Scott M. Bartell, $\mathrm{PhD}^{\mathrm{a}, \mathrm{c}}$; Argyrios Ziogas, $\mathrm{PhD}^{\mathrm{b}}$;
} Robert Bristow, MD, MBA ${ }^{d, e}$; and Verónica M. Vieira, DSc ${ }^{a, d}$

\begin{abstract}
Background: More than 14,000 women in the United States die of ovarian cancer (OC) every year. Disparities in survival have been observed by race and socioeconomic status (SES), and vary spatially even after adjusting for treatment received. This study aimed to determine the impact of geographic location on receiving treatment adherent to the NCCN Clinical Practice Guidelines in Oncology (NCCN Guidelines) for OC, independent of other predictors. Patients and Methods: Women diagnosed with all stages of epithelial OC (1996-2014) were identified through the California Cancer Registry. Generalized additive models, smoothing for residential location, were used to calculate adjusted odds ratios (ORs) and $95 \% \mathrm{Cls}$ for receiving nonadherent care throughout California. We assessed the impact of distance traveled for care, distance to closest high-quality hospital, race/ethnicity, and SES on receipt of quality care, adjusting for demographic and cancer characteristics and stratifying by disease stage. Results: Of 29,844 patients with OC, 11,419 (38.3\%) received guideline-adherent care. ORs for nonadherent care were lower in northern California and higher in Kern and Los Angeles counties. Magnitudes of associations with location varied by stage (OR range, 0.45-2.19). Living farther from a high-quality hospital increased the odds of receiving nonadherent care (OR, 1.18; $95 \% \mathrm{Cl}, 1.07-1.29)$, but travel $>32 \mathrm{~km}$ to receive care was associated with decreased odds (OR, 0.76; 95\% Cl, 0.70-0.84). American Indian/other women were more likely to travel greater distances to receive care. Women in the highest SES quintile, those with Medicare insurance, and women of non-Hispanic black race were less likely to travel far. Patients who were Asian/Pacific Islander lived the closest to a highquality hospital. Conclusions: Among California women diagnosed with $\mathrm{OC}$, living closer to a high-quality center was associated with receiving adherent care. Non-Hispanic black women were less likely to receive adherent care, and women with lower SES lived farthest from high-quality hospitals. Geographic location in California is an independent predictor of adherence to NCCN Guidelines for OC.

J Natl Compr Canc Netw 2019;17(11):1318-1329 doi: $10.6004 /$ jnccn.2019.7325
\end{abstract}

aProgram in Public Health, Susan and Henry Samueli College of Health Sciences, 'bepartment of Medicine, School of Medicine, and 'Department of Statistics, Donald Bren School of Information and Computer Sciences, University of California, Irvine, Irvine, California; ${ }^{d}$ Chao Family Comprehensive Cancer Center, Orange, California; and eDivision of Gynecologic Oncology, Department of Obstetrics and Gynecology, University of California, Irvine, School of Medicine, Orange, California.

\section{Background}

By the end of 2019, an estimated 22,530 women in the United States will be diagnosed with ovarian cancer (OC). ${ }^{1}$ Considered the most fatal of the gynecologic cancers, ${ }^{2}$ this malignancy kills approximately 14,000 US women each year. ${ }^{1}$ Fortunately, substantial advances in treatment in the past 4 decades have led to gradual but consistent improvements in survival. ${ }^{3}$ Stage-specific guidelines have been established by NCCN for best care practices in treating OC, ${ }^{4}$ and adherence to these recommendations has been validated as a significant predictor of disease-specific survival. ${ }^{5}$ Despite these evidence-based guidelines, inequities in access to and delivery of appropriate care still exist.

Although most efforts to understand the drivers of OC treatment disparities have largely focused on factors such as race and socioeconomic status (SES), ${ }^{6-13}$ there has been increasing consideration of the role that geographic location may play.,6,14-17 A study of national data from the SEER program explored spatial variations in the delivery of OC treatment for Medicare recipients and found that discrepancies existed by hospital referral region. ${ }^{14}$ In British Columbia, despite patients theoretically having equal healthcare access under a single-payer system, differences were found in treatment practices by health authority region. ${ }^{15}$ Even with an increasing consensus that receiving specialized care is critical for OC outcomes, ${ }^{6,8,14-24}$ a US nationwide study emphasized the disparities in access to gynecologic oncologists, highlighting their concentration in metropolitan centers. ${ }^{16}$ The vast geographic areas without specialists represent a geographic barrier for those who must cover greater distances to reach them.

The objective of our study was to examine how geocoded residence at diagnosis contributes to women in California with all stages of OC receiving care that is compliant with NCCN Clinical Practice Guidelines in Oncology (NCCN Guidelines) while exploring differences by race/ethnicity, SES, and insurance type. California accounts for $12 \%$ of all patients with OC diagnosed nationally and is therefore highly relevant as a standalone study setting because of the large number of patients and its racial/ethnic diversity. ${ }^{25}$ 


\section{Patients and Methods}

\section{Study Population}

We used a retrospective study design to examine the relationship between residential address at diagnosis and adherence to NCCN Guidelines. All patients with invasive epithelial OC diagnosed in California between January 1, 1996, and December 31, 2014, were ascertained from the California Cancer Registry (CCR), with follow-up data obtained through December 31, 2016. Reporting to the CCR within 6 months of diagnosis was close to $99 \%$, with follow-up nearly as high (95\%). ${ }^{26,27}$ CCR data were linked with California's Office of Statewide Health Planning and Development patient discharge data.

Women at all OC stages (FIGO stages I-IV) were eligible for inclusion. Patients aged $\geq 18$ years at diagnosis were identified in the CCR using ICD-O-3 code C56.9. Analysis was restricted to women with complete clinical information and no prior history of OC. After exclusions, a total of 29,844 women diagnosed with incident invasive epithelial OC were included in the analyses (Figure 1). The study was approved by the Institutional Review Board of the University of California, Irvine (UCI 14-66/HS\# 2014-1476).

\section{Study Data}

The primary outcome was nonadherence to stage-specific NCCN Guidelines, examined as a binary variable (adherent

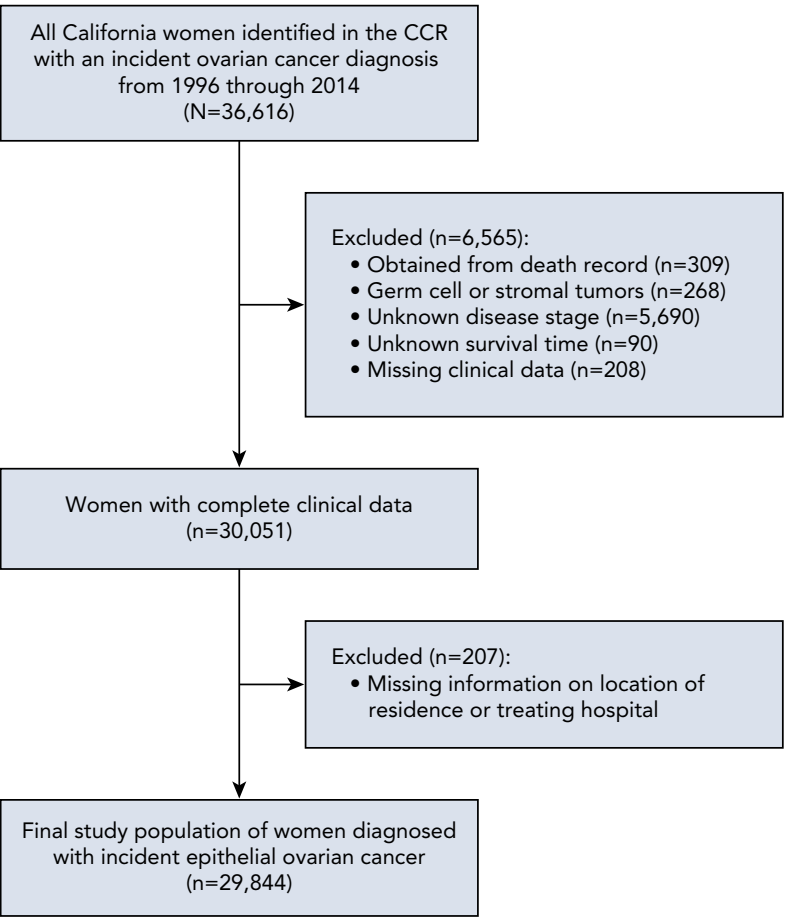

Figure 1. Study cohort selection. Abbreviation: CCR, California Cancer Registry. vs nonadherent), and required that either surgical or chemotherapy treatment be nonadherent to the current NCCN Guidelines at time of the women's respective diagnosis period. ${ }^{19,28-33}$ Surgical guideline adherence for stages I-IIIB OC was a minimum of oophorectomy ( \pm hysterectomy), pelvic or para-aortic lymph node biopsy, and omentectomy. Adherence for stages IIIC-IV disease was a minimum of oophorectomy ( \pm hysterectomy) and omentectomy. For chemotherapy, receiving no adjuvant treatment was only appropriate for early-stage and grade disease (stages IA-IB, grades 1-2). For all other stages (stages IC-IV) and grade 3 disease, multiagent chemotherapy was guideline-adherent. Chemotherapy must have been delivered subsequent to surgery, with the exception of stages IIIC-IV, in which it could have been received before or after surgery. ${ }^{19,28-33}$

Several important patient characteristics were included as predictors: age at diagnosis, race/ethnicity, SES, insurance type, marital status, Charlson-Deyo comorbidity score, diagnosis year, and tumor characteristics. ${ }^{34,35}$ Race/ethnicity was categorized as non-Hispanic white, non-Hispanic black, Hispanic, Asian/Pacific Islander, and American Indian/other. Insurance type was categorized as managed care (including private insurance), Medicare, Medicaid, other insurance, not insured, and unknown. SES was stratified into quintiles using the Yost score ${ }^{36}$ for patients diagnosed before 2006, and the Yang index ${ }^{37}$ for those diagnosed after 2006. Tumor characteristics included disease grade, size, histology type, and stage at diagnosis. The observed-to-expected (O/E) adherence ratio of patients' initial reporting hospital was included as a measure of hospital quality. ${ }^{19}$ This metric was calculated as the number of patients with OC that received NCCN-adherent care divided by the number of patients expected to receive standard care for that hospital, distributed into quartiles, and classified by annual hospital patient volume. ${ }^{19}$ Highquality hospitals were in the highest $\mathrm{O} / \mathrm{E}$ quartile and had $\geq 5$ cases/year.

To assess the role of geographic location in accessibility and potential barriers to treatment, we calculated the distance from each woman's geocoded residential address at the time of diagnosis to the geocoded location of their initial reporting hospital. We also calculated how far each woman lived from the nearest high-quality hospital. Each variable was categorized into quintiles, with distances for both measures calculated with a geographic information system using the StreetMap routing dataset in the Network Analyst extension (ArcGIS 10.4.1, Esri).

\section{Statistical Analysis}

The main predictor variable of interest was geographic location as a smooth function of women's geocoded residential location at diagnosis. We used generalized 


\begin{tabular}{|c|c|c|}
\hline Characteristic & $\begin{array}{c}\text { Adherent } \\
\text { n (\%) }\end{array}$ & $\begin{array}{c}\text { Nonadherent } \\
\text { n (\%) }\end{array}$ \\
\hline Total & $11,419(38.3)$ & $18,425(61.7)$ \\
\hline \multicolumn{3}{|l|}{ Age group, y } \\
\hline $18-44$ & 1,511 (35.9) & $2,699(64.1)$ \\
\hline $45-54$ & $2,806(43.7)$ & $3,617(56.3)$ \\
\hline $55-64$ & $3,359(46.5)$ & $3,862(53.5)$ \\
\hline$\geq 65$ & $3,743(31.2)$ & $8,247(68.8)$ \\
\hline \multicolumn{3}{|l|}{ Race/Ethnicity } \\
\hline Non-Hispanic white & 7,533 (39.8) & $11,387(60.2)$ \\
\hline Non-Hispanic black & $424(29.9)$ & $992(70.1)$ \\
\hline Hispanic & $2,020(35.1)$ & $3,729(64.9)$ \\
\hline Asian/Pacific Islander & $1,378(38.7)$ & $2,186(61.3)$ \\
\hline American Indian/other & $64(32.8)$ & $131(67.2)$ \\
\hline \multicolumn{3}{|l|}{ SES quintile } \\
\hline Lowest & $1,222(30.3)$ & $2,815(69.7)$ \\
\hline Lower-middle & $1,878(34.6)$ & $3,557(65.4)$ \\
\hline Middle & $2,374(37.5)$ & $3,950(62.5)$ \\
\hline Higher-middle & $2,769(40.4)$ & 4,091 (59.6) \\
\hline Highest & $3,176(44.2)$ & $4,012(55.8)$ \\
\hline \multicolumn{3}{|l|}{ Insurance type } \\
\hline Managed care & $5,830(41.2)$ & $8,320(58.8)$ \\
\hline Medicare & 2,438 (31.9) & $5,215(68.1)$ \\
\hline Medicaid & $1,001(36.7)$ & $1,724(63.3)$ \\
\hline Other insurance & $1,636(42.8)$ & $2,189(57.2)$ \\
\hline Not insured & 275 (30.9) & $614(69.1)$ \\
\hline Unknown & $239(39.7)$ & $363(60.3)$ \\
\hline \multicolumn{3}{|l|}{ Marital status } \\
\hline Not married & $5,029(34.2)$ & $9,659(65.8)$ \\
\hline Married & 6,390 (42.2) & $8,766(57.8)$ \\
\hline
\end{tabular}

Abbreviation: SES, socioeconomic status.

additive models (GAMs) to estimate the effect of a locally weighted regression smoother (loess) of longitude and latitude on the log odds of not receiving adherent treatment while also adjusting for covariates. ${ }^{38,39}$ Details of the methods used are described elsewhere..$^{39}$ Briefly, log odds of adherence were computed at thousands of location points throughout California while holding all other covariables constant, using the average odds for all of California as the referent group. Odds were not computed for areas with very few or no cases. ${ }^{8}$ The amount of smoothing depended on the span size, which represented the proportion of cases used locally to calculate the log odds at each point. The span size of 0.3 was chosen because it minimized the Akaike information criterion for most of the models. ${ }^{38,39}$

\begin{tabular}{|c|c|c|}
\hline Characteristic & $\begin{array}{l}\text { Adherent } \\
\text { n (\%) }\end{array}$ & $\begin{array}{c}\text { Nonadherent } \\
\text { n (\%) }\end{array}$ \\
\hline \multicolumn{3}{|c|}{ Charlson-Deyo comorbidity score } \\
\hline 0 & $5,931(41.7)$ & $8,288(58.3)$ \\
\hline 1 & $2,743(40.3)$ & $4,064(59.7)$ \\
\hline$\geq 2$ & $2,078(30.9)$ & $4,648(69.1)$ \\
\hline Unknown & 667 (31.9) & $1,425(68.1)$ \\
\hline \multicolumn{3}{|l|}{ Cancer stage } \\
\hline I & $1,720(23.8)$ & $5,518(76.2)$ \\
\hline II & $731(29.3)$ & $1,765(70.7)$ \\
\hline III & $5,943(52.8)$ & $5,320(47.2)$ \\
\hline IV & $3,025(34.2)$ & $5,822(65.8)$ \\
\hline \multicolumn{3}{|c|}{ Hospital quality measure } \\
\hline Low & $1,912(27.4)$ & $5,078(72.6)$ \\
\hline Intermediate & $6,533(37.8)$ & $10,742(62.2)$ \\
\hline High & $2,974(53.3)$ & $2,605(46.7)$ \\
\hline \multicolumn{3}{|c|}{ Distance traveled to care, $\mathrm{km}$} \\
\hline$<6$ & $1,911(32.0)$ & $4,058(68.0)$ \\
\hline $6-9$ & $2,133(35.7)$ & $3,836(64.3)$ \\
\hline $10-16$ & $2,262(37.9)$ & $3,706(62.1)$ \\
\hline $17-32$ & $2,358(39.5)$ & $3,611(60.5)$ \\
\hline$>32$ & $2,755(46.2)$ & $3,214(53.8)$ \\
\hline \multicolumn{3}{|c|}{ Closest high-quality hospital, km } \\
\hline$<9$ & $2,501(41.9)$ & $3,468(58.1)$ \\
\hline 9-14 & $2,247(37.6)$ & $3,722(62.4)$ \\
\hline $15-24$ & $2,228(37.3)$ & $3,740(62.7)$ \\
\hline $25-48$ & $2,289(38.3)$ & $3,680(61.7)$ \\
\hline$>48$ & $2,154(36.1)$ & $3,815(63.9)$ \\
\hline
\end{tabular}

Abbreviation: SES, socioeconomic status.

The base model examined the effect of residential location while adjusting only for age and cancer characteristics at diagnosis. A fully adjusted model also adjusted for demographic and treatment factors: SES, race/ethnicity, insurance type, marital status, quality of reporting hospital, comorbidities, and the 2 distance variables (ie, distance traveled to hospital and distance to closest high-quality hospital). Any differences in geographic areas of increased or decreased risk between the base and the fully adjusted models indicated that the additional demographic and treatment factors were affecting geographic variation in adherent care. We also conducted stage-stratified analyses. Permutation tests were used to calculate a global $P$ value for the importance of location. Color maps for each model displayed the odds ratios (ORs) for treatment nonadherence throughout California, with contour lines delineating 


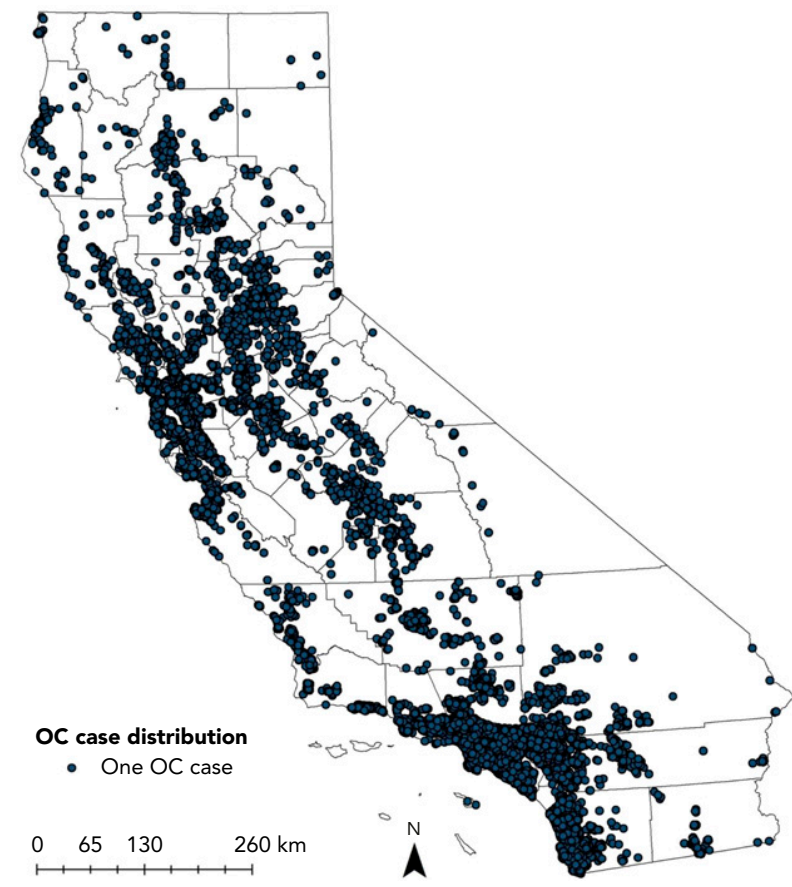

Figure 2. Epithelial OC case distribution in California, 1996-2014. Abbreviation: OC, ovarian cancer.

geographic areas that excluded ORs of 1 . We also conducted chi-square tests for differences between racial/ ethnic, SES, and insurance groups across the distribution of distance variables. Statistical modeling and mapping

A
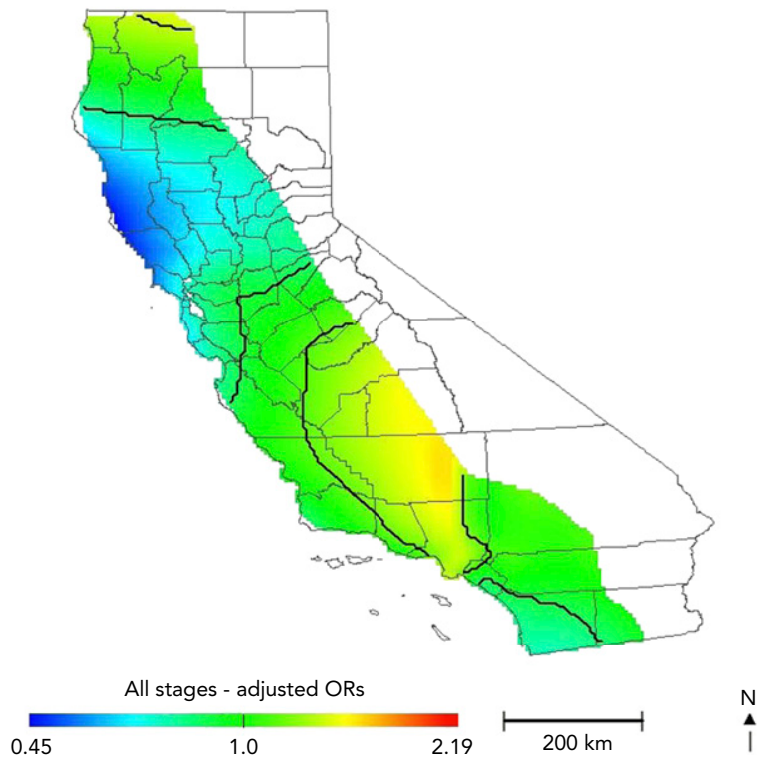

were performed in $\mathrm{R}$ version 3.4.0 using the MapGAM package (R Foundation).

\section{Results}

Patient characteristics are detailed in Table 1, with the case distribution shown in Figure 2. Of 29,844 women included in the analysis, 9,734 (32.6\%) were diagnosed with OC at early stages (stages I and II). Most of the population was non-Hispanic white $(63.4 \%)$, and the median age at diagnosis was 60 years. Only 11,419 (38.3\%) of all patients received care adherent to the NCCN Guidelines. Women with stage III disease were more likely to receive adherent care than those diagnosed with early-stage or stage IV OC $(52.8 \%$ vs $25.2 \%$ and $34.2 \%$, respectively).

\section{Spatial Analysis of Treatment Adherence}

Residential location was significantly associated with nonadherence to NCCN Guidelines among California women diagnosed with OC. All analyses, including stagestratified models, resulted in a highly significant global test for location $(P<.001)$. Compared with the base model ORs adjusted for only age and cancer characteristics for all stages (OR range, 0.46-1.57), the fully adjusted ORs were attenuated in some locations but increased in others (OR range, 0.70-1.89). Figure 3 shows that the protective effects observed in northern California were attenuated and no longer present in the San Francisco Bay area after full adjustment. Although the reduced risk observed in
B
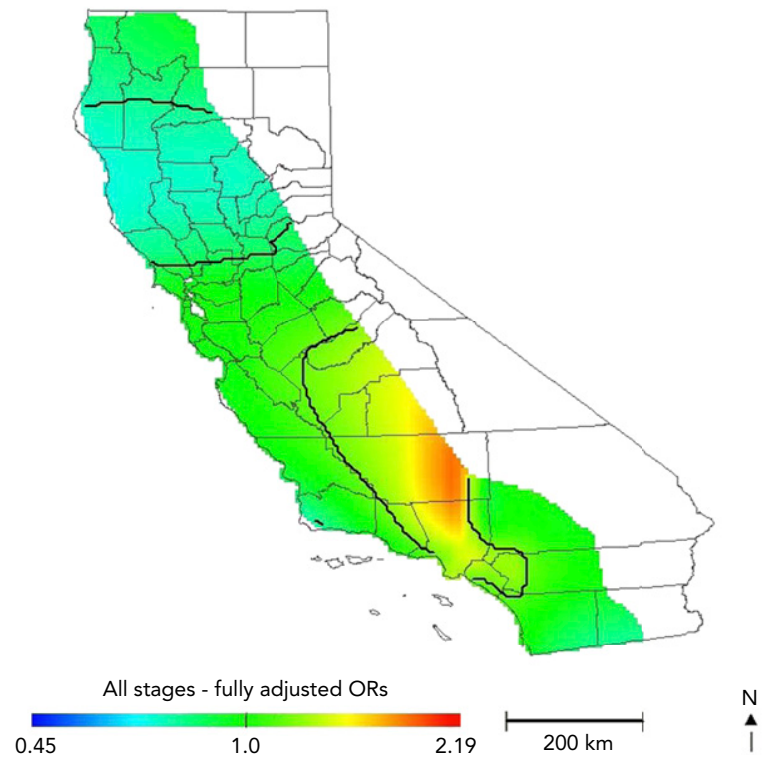

Figure 3. Odds of receiving nonadherent care for ovarian cancer in California: effect of geographic location. (A) Base and (B) fully adjusted models. The base model is adjusted for age and cancer characteristics only. Contour lines delineate geographic areas that exclude ORs of 1. Abbreviation: OR, odds ratio. 
A

Base model
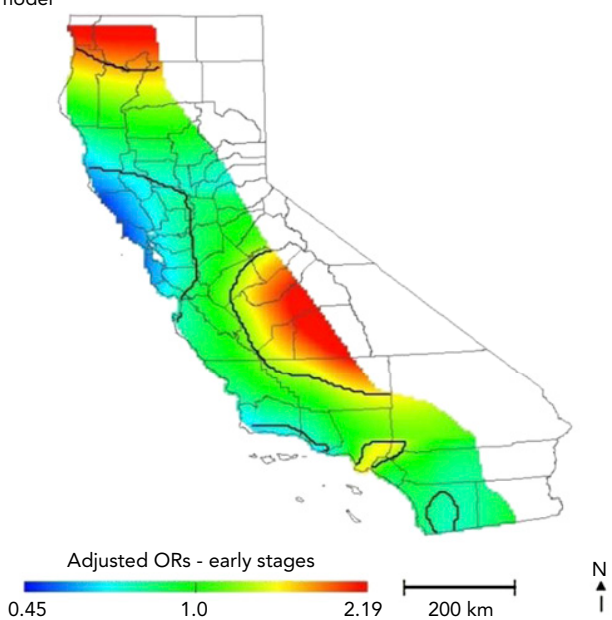

B

Base model

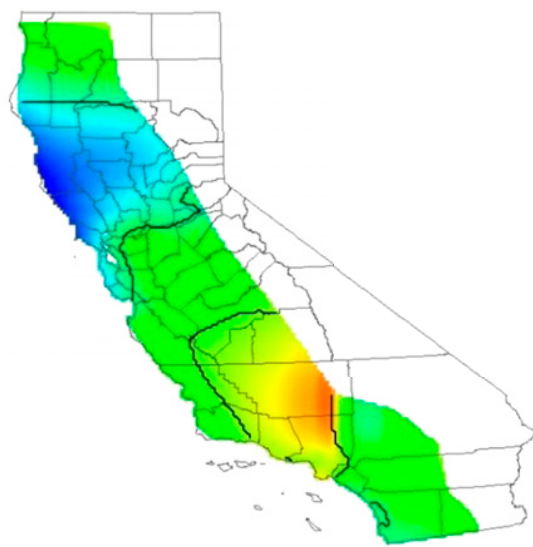

C

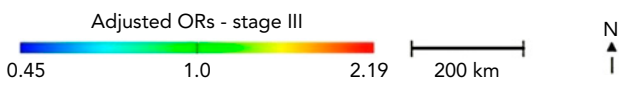

Base model
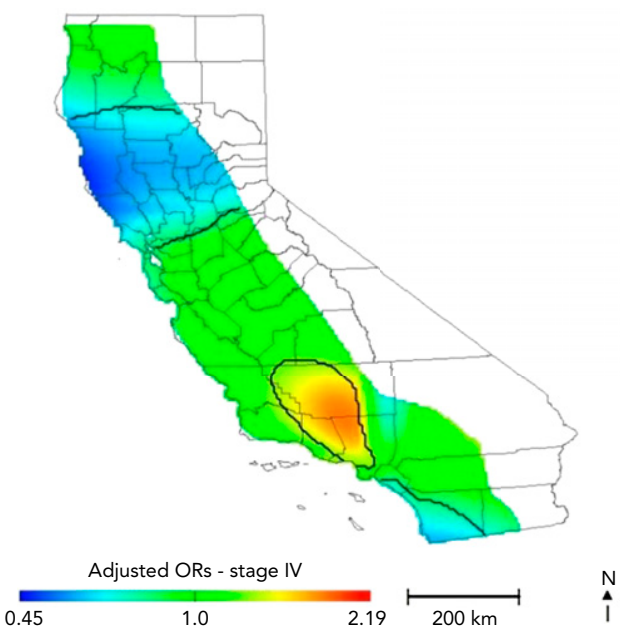
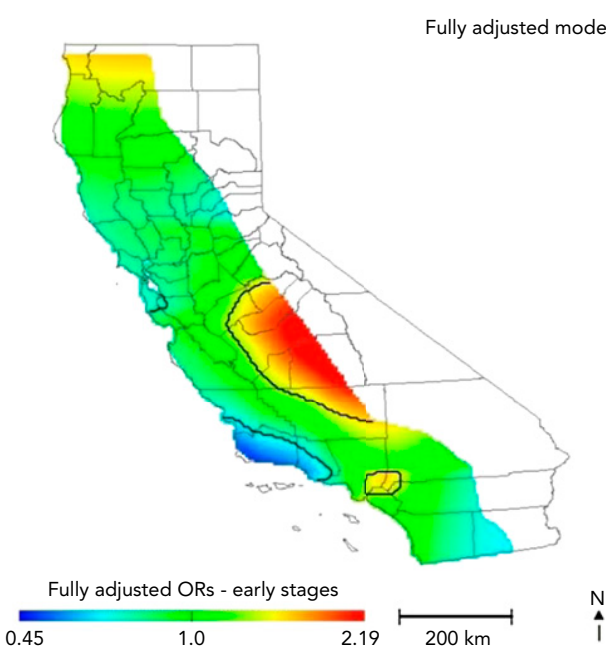

Fully adjusted model

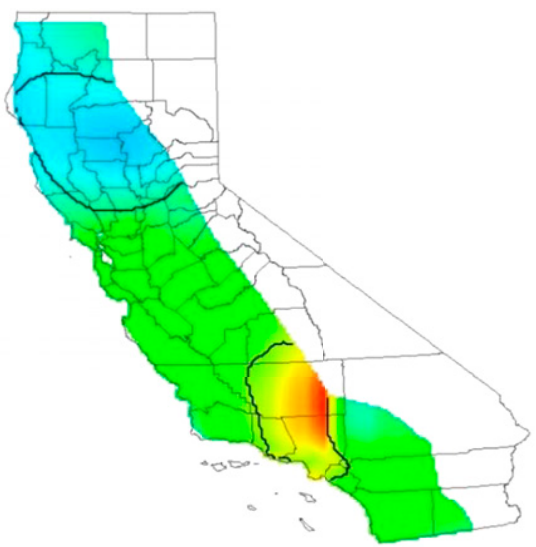

Fully adjusted ORs - stage III

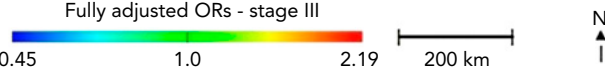

Fully adjusted model

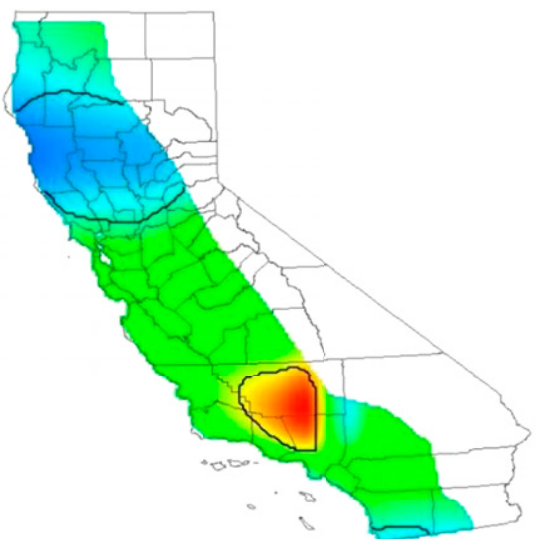

Fully adjusted ORs - stage IV

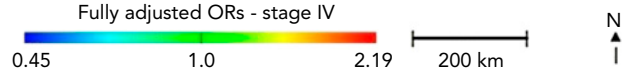

Figure 4. Odds of receiving nonadherent care for ovarian cancer in California: effect of geographic location, stratified by stage: (A) early stages (ie, stages I and II), (B) stage III, and (C) stage IV. Contour lines delineate geographic areas that exclude ORs of 1. Base model is adjusted for age and cancer characteristics only.

Abbreviation: OR, odds ratio. 


\begin{tabular}{|c|c|}
\hline Characteristic & OR $(95 \% \mathrm{Cl})$ \\
\hline Age & $1.02(1.02-1.02)$ \\
\hline \multicolumn{2}{|l|}{ Tumor size, mm } \\
\hline$<50$ & Ref \\
\hline $50-99$ & $0.93(0.85-1.02)$ \\
\hline$\geq 100$ & $0.91(0.83-0.99)$ \\
\hline Unknown & $1.12(1.03-1.22)$ \\
\hline \multicolumn{2}{|l|}{ Disease grade } \\
\hline 1 & Ref \\
\hline 2 & $1.00(0.89-1.13)$ \\
\hline 3 & $0.85(0.76-0.95)$ \\
\hline 4 & $0.73(0.65-0.83)$ \\
\hline Unknown & $2.25(2.00-2.54)$ \\
\hline \multicolumn{2}{|l|}{ Cancer stage } \\
\hline I & Ref \\
\hline II & $0.75(0.68-0.84)$ \\
\hline III & $0.25(0.23-0.27)$ \\
\hline IV & $0.33(0.30-0.36)$ \\
\hline \multicolumn{2}{|l|}{ Histology } \\
\hline Serous & Ref \\
\hline Mucinous & $1.40(1.24-1.58)$ \\
\hline Endometrioid & $1.22(1.11-1.34)$ \\
\hline Clear-cell & $0.91(0.81-1.03)$ \\
\hline Adenocarcinoma, NOS & $2.89(2.59-3.22)$ \\
\hline Others & $1.78(1.66-1.91)$ \\
\hline \multicolumn{2}{|l|}{ Race/Ethnicity } \\
\hline Non-Hispanic white & Ref \\
\hline Non-Hispanic black & $1.21(1.06-1.39)$ \\
\hline Hispanic & $1.01(0.93-1.09)$ \\
\hline Asian/Pacific Islander & $1.02(0.93-1.11)$ \\
\hline American Indian/other & $1.47(1.05-2.05)$ \\
\hline \multicolumn{2}{|l|}{ SES } \\
\hline Lowest & $1.28(1.16-1.42)$ \\
\hline Lower-middle & $1.15(1.06-1.26)$ \\
\hline Middle & $1.09(1.01-1.19)$ \\
\hline Higher-middle & $1.06(0.98-1.14)$ \\
\hline Highest & Ref \\
\hline
\end{tabular}

Abbreviations: NOS, not otherwise specified; OR, odds ratio; SES socioeconomic status.

the southernmost portion of California was no longer present after full adjustment, risk in northern Los Angeles County and western Kern County increased. Spatial variability in risk of nonadherent treatment with the fully adjusted models indicated geographic disparities in adherent treatment that were not explained by

\begin{tabular}{|c|c|}
\hline Characteristic & OR $(95 \% \mathrm{Cl})$ \\
\hline \multicolumn{2}{|l|}{ Insurance type } \\
\hline Managed care & Ref \\
\hline Medicare & $1.10(1.03-1.19)$ \\
\hline Medicaid & $1.04(0.94-1.15)$ \\
\hline Other insurance & $1.01(0.93-1.10)$ \\
\hline Not insured & $1.34(1.14-1.58)$ \\
\hline Unknown & $0.99(0.82-1.20)$ \\
\hline \multicolumn{2}{|l|}{ Marital status } \\
\hline Not married & Ref \\
\hline Married & $0.85(0.81-0.90)$ \\
\hline \multicolumn{2}{|c|}{ Charlson-Deyo comorbidity score } \\
\hline 0 & Ref \\
\hline 1 & $0.99(0.92-1.05)$ \\
\hline$\geq 2$ & $1.19(1.10-1.28)$ \\
\hline Unknown & $1.26(1.13-1.41)$ \\
\hline Year of diagnosis & $1.01(1.00-1.01)$ \\
\hline \multicolumn{2}{|c|}{ Hospital quality measure } \\
\hline Low & $2.57(2.35-2.81)$ \\
\hline Intermediate & $1.76(1.64-1.89)$ \\
\hline High & Ref \\
\hline \multicolumn{2}{|c|}{ Distance traveled to care, $\mathrm{km}$} \\
\hline$<6$ & Ref \\
\hline $6-9$ & $0.92(0.85-1.00)$ \\
\hline $10-16$ & $0.89(0.82-0.97)$ \\
\hline $17-32$ & $0.91(0.84-1.00)$ \\
\hline$>32$ & $0.76(0.70-0.84)$ \\
\hline \multicolumn{2}{|c|}{ Closest high-quality hospital, $\mathrm{km}$} \\
\hline$<9$ & Ref \\
\hline $9-14$ & $1.06(0.97-1.15)$ \\
\hline $15-24$ & $1.05(0.97-1.15)$ \\
\hline $25-48$ & $1.13(1.04-1.23)$ \\
\hline$>48$ & $1.18(1.07-1.29)$ \\
\hline
\end{tabular}

Abbreviations: NOS, not otherwise specified; OR, odds ratio; SES, socioeconomic status.

distance to the initial reporting hospital, distance from the nearest high-quality hospital, or the other demographic and treatment variables included in these analyses.

Patterns of geographic risk for nonadherence to NCCN Guidelines varied across the different disease stage-stratified analyses. Regions of increased and decreased risk in the early-stage analyses differed greatly from those for the other stages (compare Figure 3 vs Figure 4). When controlling for age and cancer characteristics alone, we identified areas of increased risk for 
nonadherent treatment of early-stage OC in the midCentral Valley and decreased risk in northern California (OR range, 0.49-2.90). After full adjustment of the earlystage model, there was no longer an association in northern California and San Diego County; however, a larger portion of Ventura and Santa Barbara counties on the Central Coast showed a decreased risk of noncompliant care (OR range, 0.49-2.90). Models for stages III and IV displayed similar patterns to those of all stages combined, although areas of higher and lower risk were smaller (Figure 4B, C) and the magnitude of ORs were attenuated (OR ranges, $0.61-2.13$ and $0.47-1.86$ for stages III and IV, respectively).

Associations between all-stage nonadherent care and additional variables included in the spatial model are presented in Table 2. Increasing distance traveled to receive care decreased nonadherence ORs. Compared with patients living $<6 \mathrm{~km}$ from their initial reporting facility, those traveling $>32 \mathrm{~km}$ for treatment had decreased odds (OR, 0.76; 95\% CI, 0.70-0.84) of receiving care that deviated from the NCCN Guidelines. Increasing distance traveled to receive care was significantly protective against receiving nonadherent care for those with early-stage disease (Table 3). Compared with living within $9 \mathrm{~km}$ of a high-quality hospital, living $>48 \mathrm{~km}$ from a high-quality hospital was a significant deterrent to receiving adherent care for women diagnosed with $\mathrm{OC}$ at an early stage. Patterns with distance were similar for stages III and IV but generally not significant (data not shown).

\section{Geographic Disparities}

The distributions of distance traveled to the reporting hospital by patient characteristics are shown in Table 4 . Greater proportions of women treated at high-quality facilities traveled farther for care. Among women treated at a high-quality hospital, more than one-third (38.1\%) lived within $9 \mathrm{~km}$, whereas only $9.3 \%$ lived $>48 \mathrm{~km}$ away (Table 5). In contrast, women treated at lower-quality hospitals tended to live farther from high-quality hospitals (31.4\% in farthest category vs $11.8 \%$ in closest).

Non-Hispanic white and American Indian/other women constituted the largest proportions of women traveling $>32 \mathrm{~km}$ for care (see Table 4 ). Non-Hispanic black women were the least likely to travel greater distances for care across all analyses. Overall, women diagnosed at stage IV disease were the least likely to travel far, regardless of race, SES, or insurance (data not shown). Note that Asian/Pacific Islanders (30.4\%) and non-Hispanic black women $(21.8 \%)$ constituted the largest proportion of those living $<9 \mathrm{~km}$ from the closest high-quality hospital (see Table 5). Additionally, $<10 \%$ of women of the highest SES lived $>48 \mathrm{~km}$ from a high-quality hospital, compared with $>25 \%$ in each of the lower SES quintiles.

\begin{tabular}{|lc|}
\hline $\begin{array}{l}\text { Table 3. Multivariate Analysis of Treatment } \\
\text { Nonadherence for Stages I and II }\end{array}$ \\
\hline Variable & \multicolumn{1}{c|}{ OR $^{\mathbf{a}}(95 \% \mathrm{Cl})$} \\
\hline Distance traveled to care, $\mathrm{km}$ & $0.82(0.69-0.96)$ \\
\hline$<6$ & $0.83(0.70-0.98)$ \\
\hline $6-9$ & $0.77(0.66-0.91)$ \\
\hline $10-16$ & $0.57(0.49-0.68)$ \\
\hline $17-32$ & \\
\hline$>32$ & Ref \\
\hline Closest high-quality hospital, km & $0.96(0.82-1.12)$ \\
\hline$<9$ & $1.02(0.87-1.20)$ \\
\hline $9-14$ & $1.14(0.97-1.34)$ \\
\hline $15-24$ & $1.25(1.05-1.49)$ \\
\hline $25-48$ & \\
\hline$>48$ & \\
\hline
\end{tabular}

Abbreviation: $\mathrm{OR}$, odds ratio.

aOR adjusted for geographic location, age, race/ethnicity, socioeconomic status, insurance, marital status, Charlson-Deyo comorbidity score, stage, and hospital quality.

\section{Discussion}

Overall, just more than one-third of our study cohort received NCCN Guideline-adherent care. This was possibly a result of comorbidities, disease progression, lack of access to specialized facilities, and lower SES. ${ }^{5-7,12,13,40}$ Studies examining other cancers have shown similar low rates $(<50 \%)$ of adherence to NCCN Guidelines. ${ }^{41,42}$ Our study found residential location to be significantly associated with the likelihood of receiving guidelineadherent treatment among women diagnosed with OC. Because of an increasing awareness of the impact of residential location on health and the development of more sophisticated analysis tools, the value of geospatial research in cancer is increasing. ${ }^{43}$ With the availability of geocoded addresses and the use of GAMs, we identified disparities within California resulting in certain women being more or less at risk for receiving nonadherent care, despite adjustment for numerous important factors, and further showed that the impact of location depended on disease stage at diagnosis. This methodology was previously used to examine late-stage OC survival disparities across California census tracts. ${ }^{8}$

Differences in spatial patterns of care are increasingly being recognized in the OC literature. One populationbased study exploring geographic patterns in treatment delivery and epithelial OC mortality by health referral regions found hospital region to be associated with regional discrepancies in cancer-specific surgery, with women in more remote areas less likely to receive this surgery. ${ }^{14}$ Our results also show that women living in remote areas of central California, especially those 


\section{Table 4. Comparison of Patient Characteristics by Distance Traveled to Receive Care $(\mathrm{N}=29,844)$}

\begin{tabular}{|c|c|c|c|c|c|c|}
\hline & $\begin{array}{l}<6 \mathrm{~km} \\
\mathrm{n}(\%)\end{array}$ & $\begin{array}{c}\text { 6-9 km } \\
\mathrm{n}(\%)\end{array}$ & $\begin{array}{c}10-16 \text { km } \\
\text { n (\%) }\end{array}$ & $\begin{array}{c}\text { 17-32 km } \\
\text { n (\%) }\end{array}$ & $\begin{array}{c}>32 \text { km } \\
\text { n (\%) }\end{array}$ & $\begin{array}{c}\text { Total } \\
\mathbf{n}\end{array}$ \\
\hline \multicolumn{7}{|l|}{ Age group, y } \\
\hline $18-44$ & 737 (17.5) & 815 (19.4) & $887(21.1)$ & $930(22.1)$ & $841(20.0)$ & 4,210 \\
\hline $55-64$ & $1,252(17.3)$ & $1,320(18.3)$ & $1,432(19.8)$ & $1,535(21.3)$ & $1,682(23.3)$ & 7,221 \\
\hline$\geq 65$ & $2,832(23.6)$ & $2,704(22.6)$ & $2,346(19.6)$ & $2,083(17.4)$ & $2,025(16.9)$ & 11,990 \\
\hline Non-Hispanic black & $291(20.6)$ & $293(20.7)$ & $345(24.4)$ & $300(21.2)$ & $187(13.2)$ & 1,416 \\
\hline Hispanic & $1,099(19.1)$ & $1,205(21.0)$ & $1,241(21.6)$ & $1,226(21.3)$ & $978(17.0)$ & 5,749 \\
\hline Asian/Pacific Islander & $715(20.1)$ & $718(20.1)$ & $804(22.6)$ & $750(21.0)$ & $577(16.2)$ & 3,564 \\
\hline American Indian/other & $33(16.9)$ & $37(19.0)$ & $33(16.9)$ & $36(18.5)$ & $56(28.7)$ & 195 \\
\hline \multicolumn{7}{|l|}{ SES quintile } \\
\hline Highest & $1,322(18.4)$ & $1,599(22.2)$ & $1,480(20.6)$ & $1,581(22.0)$ & $1,206(16.8)$ & 7,188 \\
\hline \multicolumn{7}{|l|}{ Insurance type } \\
\hline Managed care & $2,528(17.9)$ & $2,763(19.5)$ & $2,926(20.7)$ & $3,111(22.0)$ & $2,822(19.9)$ & 14,150 \\
\hline Medicare & $1,913(25.0)$ & $1,687(22.0)$ & $1,423(18.6)$ & $1,194(15.6)$ & $1,436(18.8)$ & 7,653 \\
\hline Medicaid & $604(22.2)$ & $532(19.5)$ & $534(19.6)$ & $563(20.7)$ & $492(18.1)$ & 2,725 \\
\hline Other insurance & $675(17.6)$ & $717(18.7)$ & $730(19.1)$ & $764(20.0)$ & $939(24.5)$ & 3,825 \\
\hline Not insured & $145(16.3)$ & $155(17.4)$ & $202(22.7)$ & $223(25.1)$ & $164(18.4)$ & 889 \\
\hline Unknown & $104(17.3)$ & $115(19.1)$ & $153(25.4)$ & $114(18.9)$ & $116(19.3)$ & 602 \\
\hline \multicolumn{7}{|l|}{ Marital status } \\
\hline Not married & $3,300(22.5)$ & $3,051(20.8)$ & $2,905(19.80$ & $2,821(19.2)$ & $2,611(17.8)$ & 14,688 \\
\hline Married & $2,669(17.6)$ & $2,918(19.3)$ & $3,063(20.2)$ & $3,148(20.8)$ & $3,358(22.2)$ & 15,156 \\
\hline$\|$ & $473(19.0)$ & $480(19.2)$ & $461(18.5)$ & $548(22.0)$ & $534(21.4)$ & 2,496 \\
\hline III & $2,148(19.1)$ & $2,161(19.2)$ & $2,203(19.6)$ & $2,238(19.9)$ & $2,513(22.3)$ & 11,263 \\
\hline $\mathrm{IV}$ & $2,003(22.6)$ & $1,937(21.9)$ & $1,819(20.6)$ & $1,641(18.5)$ & $1,447(16.4)$ & 8,847 \\
\hline \multicolumn{7}{|l|}{ NCCN Guideline adherence } \\
\hline Adherent & $1,911(16.7)$ & $2,133(18.7)$ & $2,262(19.8)$ & $2,358(20.6)$ & $2,755(24.1)$ & 11,419 \\
\hline Nonadherent & $4,058(22.0)$ & $3,836(20.8)$ & $3,706(20.1)$ & $3,611(19.6)$ & $3,214(17.4)$ & 18,425 \\
\hline \multicolumn{7}{|l|}{ Hospital quality measure } \\
\hline Low & $2,157(30.9)$ & $1,594(22.8)$ & $1,315(18.8)$ & $1,121(16.0)$ & $803(11.5)$ & 6,990 \\
\hline Intermediate & $3,036(17.6)$ & $3,488(20.2)$ & $3,590(20.8)$ & $3,597(20.8)$ & $3,564(20.6)$ & 17,275 \\
\hline High & $776(13.9)$ & $887(15.9)$ & $1,063(19.1)$ & $1,251(22.4)$ & $1,602(28.7)$ & 5,579 \\
\hline \multicolumn{7}{|c|}{ Closest high-quality hospital, km } \\
\hline$<9$ & $1,843(30.9)$ & $1,850(31.0)$ & $975(16.3)$ & $809(13.6)$ & 492 (8.2) & 5,969 \\
\hline $9-14$ & $1,100(18.4)$ & $1,240(20.8)$ & $2,003(33.6)$ & $1,109(18.6)$ & $517(8.70$ & 5,969 \\
\hline $15-24$ & $860(14.4)$ & $1,082(18.1)$ & $1,404(23.5)$ & $1,879(31.5)$ & $743(12.4)$ & 5,968 \\
\hline $25-48$ & $1,023(17.1)$ & $1,052(17.6)$ & $862(14.4)$ & $1,375(23.0)$ & $1,657(27.8)$ & 5,969 \\
\hline$>48$ & $1,143(19.1)$ & $745(12.5)$ & $724(12.1)$ & $797(13.4)$ & $2,560(42.9)$ & 5,969 \\
\hline
\end{tabular}

Statistical significance of differences between groups was calculated using chi-square tests. $P$ values were $<.001$ for all categories. Abbreviation: SES, socioeconomic status. 


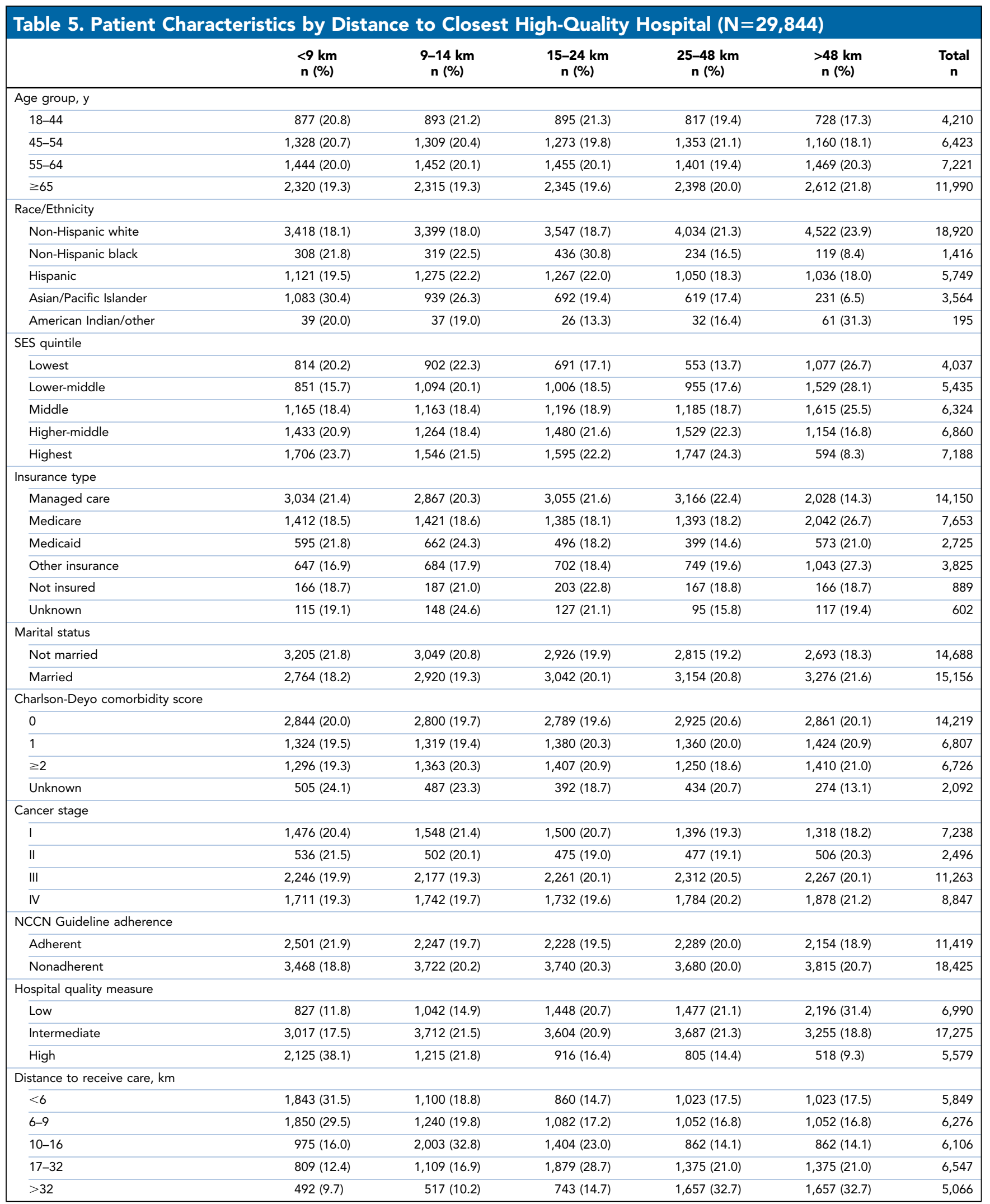

Statistical significance of differences between groups was calculated using chi-square tests. $P$ values were $<.001$ for all categories. Abbreviation: SES, socioeconomic status. 
diagnosed with $\mathrm{OC}$ at an early stage, were more vulnerable to receiving substandard care. Although there was a low density of high-quality centers in nonmetropolitan areas, the risk of treatment nonadherence in California differed depending on residential location. Although patients living in rural areas of northern California had favorable odds, those residing in counties encompassing greater Los Angeles received nonstandard care despite the availability of high-quality centers.

It is well documented that the location of initial treatment of OC is important, with high-volume and high-quality centers showing superior outcomes. ${ }^{19,20,22,44}$ A comprehensive cancer center examining its own patients' travel distance found that those residing farthest from the hospital had worse cervical cancer outcomes, ${ }^{45}$ yet a similar analysis of patients with gynecologic malignancies treated at an NCI-designated center found that those living $<10$ miles away were less likely to be treatment-compliant, although those making the longest journey had greater mortality before treatment completion. ${ }^{46}$ We found that women were more likely to access a high-quality hospital if they lived close to one, an association similarly observed by Tracey et al, ${ }^{17}$ who found that more than half of women living within $5 \mathrm{~km}$ of high-quality hospitals used these facilities compared with $16 \%$ of women residing in the farthest quintile. ${ }^{17}$

The considerable financial challenges that patients with cancer already face coupled with the additional burden associated with travel to treatment must be acknowledged. ${ }^{46}$ Travel is a geographic barrier to treatment and may disproportionately affect patients of lower SES, ${ }^{47}$ a point illustrated by their overall remoteness from high-quality centers according to our results. The implications of geographic access and travel are worth noting, given that women of lower SES and with safety-net or no insurance were less likely to travel for care, obtain care at quality centers, or receive NCCN Guideline-adherent treatment. Furthermore, women may choose to stay local for care. One study reported that approximately $20 \%$ of women indicated that they would not travel $>50$ miles for care, despite the potential survival advantages. ${ }^{48}$ This may be particularly true for older women, those with comorbidities, and those with limited social support. In particular, greater distances may be less viable for women who may be managing multiple conditions. ${ }^{49} \mathrm{We}$ found that women with $\geq 2$ comorbidities and aged $>65$ years were less likely to travel farther, which is consistent with prior studies showing that older age is associated with shorter

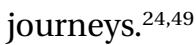

Our study has several noteworthy features, including the large sample size, with almost 20 years of data available from the CCR, a registry with shown reliability. In addition, the investigation of geocoded residential location and its differing effects on OC treatment adherence by disease stage and social demographics is novel. Unlike previous studies that used ZIP code and census block variables as spatial proxies, using an individual-level measure of patient location allowed for a more accurate assessment of the effect of geographic location. Furthermore, the Network Analyst tool in the geographic information system provided a more precise calculation of travel distance. We were also able to adjust for several important covariates, including comorbidity, which has been shown to be a main reason for failure to complete chemotherapy ${ }^{40}$ Finally, the GAM framework is particularly useful for investigating nonlinear geographic disparities while accounting for known risk factors.

This study was limited by the potential for reporting bias and the presence of unmeasured confounders given reliance on previously collected registry data. Furthermore, the collection and interpretation of CCR data may have been limited by the possibility that reporting facilities are not the main treating hospital, satellite hospitals may report under one hospital, and chemotherapy treatment may be underreported. However, these potential limitations are uncommon and unlikely to influence the results in this secondary analysis of large population-based data. In addition, we could not account for several potentially important access characteristics, such as travel times and the use or availability of public transportation. To compute distances, we assumed that patients would drive the shortest route between their residence and hospitals. However, when reliable transportation is unavailable, difficult, or expensive, travel may pose additional burdens to patients of lower SES. Another limitation was that the CCR does not collect information on treating physicians' case volume or medical specialty. These characteristics may vary geographically and have been previously found to be predictors of treatment adherence and survival. ${ }^{50-52}$

\section{Conclusions}

Quality care is vital to decreasing OC mortality, yet most women with OC do not receive it. Future research should examine how location differentially affects access to care and impacts survival. Non-Hispanic black women, women of lower SES, and nonmarried women were less likely to travel far for care and were more likely to receive nonadherent treatment. Spatial analyses of geographic barriers using linear and nonlinear methods may provide an opportunity for targeted intervention to broaden access to care among vulnerable populations. Providing transportation, opening satellite clinics, employing patient navigators, and ensuring that those services are covered 
by all insurance carriers are potential avenues to facilitate access to high-quality care, ultimately improving survival of women with OC overall. ${ }^{16,45}$

Submitted January 7, 2019; accepted for publication June 3, 2019

Author contributions: Study concept and design: Bristow, Vieira. Data acquisition and assembly: Chang, Ziogas. Data analysis: Villanueva. Technical support: Bartell, Vieira. Interpretation of results: All authors. Manuscript preparation: Villanueva, Vieira. Final manuscript review and approval: All authors.

Disclosures: The authors have disclosed that they have not received any financial consideration from any person or organization to support the preparation, analysis, results, or discussion of this article. This research was supported by funding from the National Center on Minority Health and Health Disparities (R01MD009697).

Correspondence: Carolina Villanueva, MPH, Program in Public Health, Susan and Henry Samueli College of Health Sciences, University of California, Irvine, 2040C Anteater Instruction and Research Building, Irvine, CA 92697. Email: hcvillan@uci.edu

\section{References}

1. Siegel RL, Miller KD, Jemal A. Cancer statistics, 2019. CA Cancer J Clin 2018;69:7-34

2. Grossman DC, Curry SJ, Owens DK, et al. Screening for ovarian cancer: US Preventive Services Task Force recommendation statement. JAMA 2018; 319:588-594.

3. Terplan M, Schluterman N, McNamara EJ, et al. Have racial disparities in ovarian cancer increased over time? An analysis of SEER data. Gynecol Oncol 2012;125:19-24.

4. Motzer RJ, Jonasch E, Agarwal N, et al. Ovarian cancer, Version 2. 2014: featured updates to the NCCN Guidelines. J Natl Compr Canc Netw 2014;12:175-181.

5. Bristow RE, Chang J, Ziogas A, et al. Adherence to treatment guidelines for ovarian cancer as a measure of quality care. Obstet Gynecol 2013;121: 1226-1234.

6. Bristow RE, Chang J, Ziogas A, et al. Spatial analysis of adherence to treatment guidelines for advanced-stage ovarian cancer and the impact of race and socioeconomic status. Gynecol Oncol 2014; 134:60-67

7. Bristow RE, Chang J, Ziogas A, et al. Sociodemographic disparities in advanced ovarian cancer survival and adherence to treatment guidelines. Obstet Gynecol 2015;125:833-842.

8. Bristow RE, Chang J, Ziogas A, et al. Spatial analysis of advancedstage ovarian cancer mortality in California. Am J Obstet Gynecol 2015;213:43.e1-43.e8.

9. Hodeib M, Chang J, Liu F, et al. Socioeconomic status as a predictor of adherence to treatment guidelines for early-stage ovarian cancer. Gynecol Oncol 2015;138:121-127.

10. Collins Y, Holcomb K, Chapman-Davis E, et al. Gynecologic cancer disparities: a report from the Health Disparities Taskforce of the Society of Gynecologic Oncology. Gynecol Oncol 2014; 133:353-361.

11. Cronin KA, Howlader N, Stevens JL, et al. Racial disparities in the receipt of guideline care and cancer deaths for women with ovarian cancer. Cancer Epidemiol Biomarkers Prev 2019;28:539-545.

12. Bristow RE, Powell MA, Al-Hammadi N, et al. Disparities in ovarian cancer care quality and survival according to race and socioeconomic status. J Natl Cancer Inst 2013;105:823-832.

13. Long B, Chang J, Ziogas A, et al. Impact of race, socioeconomic status, and the health care system on the treatment of advanced-stage ovarian cancer in California. Am J Obstet Gynecol 2015;212: 468.e1-468.e9

14. Fairfield KM, Lucas FL, Earle CC, et al. Regional variation in cancerdirected surgery and mortality among women with epithelial ovarian cancer in the Medicare population. Cancer 2010;116:4840-4848.

15. Dehaeck U, McGahan CE, Santos JL, et al. The impact of geographic variations in treatment on outcomes in ovarian cancer. Int J Gynecol Cancer 2013;23:282-287

16. Stewart SL, Cooney D, Hirsch S, et al. The effect of gynecologic oncologist availability on ovarian cancer mortality. World J Obstet Gynecol 2014;3:71-77.

17. Tracey E, Hacker NF, Young J, et al. Effects of access to and treatment in specialist facilities on survival from epithelial ovarian cancer in Australian women: a data linkage study. Int J Gynecol Cancer 2014;24 1232-1240.

18. Cowan RA, O'Cearbhaill RE, Gardner GJ, et al. Is it time to centralize ovarian cancer care in the United States? Ann Surg Oncol 2016;23: 989-993.

19. Galvan-Turner VB, Chang J, Ziogas A, et al. Observed-to-expected ratio for adherence to treatment guidelines as a quality of care indicator for ovarian cancer. Gynecol Oncol 2015;139:495-499.
20. Bristow RE, Zahurak ML, Diaz-Montes TP, et al. Impact of surgeon and hospital ovarian cancer surgical case volume on in-hospital mortality and related short-term outcomes. Gynecol Oncol 2009;115:334-338.

21. Polsky D, Armstrong KA, Randall TC, et al. Variations in chemotherapy utilization in ovarian cancer: the relative contribution of geography. Health Serv Res 2006;41:2201-2218

22. Bristow RE, Chang J, Ziogas A, et al. High-volume ovarian cancer care: survival impact and disparities in access for advanced-stage disease. Gynecol Oncol 2014;132:403-410.

23. Chase DM, Fedewa S, Chou TS, et al. Disparities in the allocation of treatment in advanced ovarian cancer: are there certain patient characteristics associated with nonstandard therapy? Obstet Gynecol 2012;119. 68-77.

24. Wasif N, Chang YH, Pockaj BA, et al. Association of distance traveled for surgery with short- and long-term cancer outcomes. Ann Surg Oncol 2016;23:3444-3452.

25. American Cancer Society. Cancer Statistics Center. Ovary. Available at: https://cancerstatisticscenter.cancer.org/?_ga $=2.71867859$. 1377176935.1542797564-800158735.1542797564\#!/cancer-site/Ovary. Accessed October 2, 2019.

26. Parikh-Patel A, Allen M, Wright WE. Validation of self-reported cancers in the California Teachers Study. Am J Epidemiol 2003;157:539-545.

27. California Cancer Registry. Information for patients. Available at: https:// www.ccrcal.org/learn-about-ccr/about-cancer-registries/information-forpatients/\#how\%20complete\%20are\%20ccr\%20data. Accessed June 7, 2019.

28. Ozols RF. Update of the NCCN ovarian cancer practice guidelines. Oncology (Williston Park) 1997;11:95-105.

29. Morgan R Jr, Alvarez R, Armstrong D, et al. NCCN Practice Guidelines for Ovarian Cancer. Version 2000. To view the most recent version, visit NCCN.org.

30. Morgan R Jr, Alvarez R, Armstrong D, et al. NCCN Clinical Practice Guidelines in Oncology: Ovarian Cancer. Version 1.2002. To view the most recent version, visit NCCN.org.

31. Morgan R Jr, Alvarez R, Armstrong D. NCCN Clinical Practice Guidelines in Oncology: Ovarian Cancer. Version 1.2005. To view the most recent version, visit NCCN.org.

32. Morgan RJ Jr, Alvarez RD, Armstrong DK, et al. Ovarian cancer, version 3.2012. J Natl Compr Canc Netw 2012;10:1339-1349.

33. Morgan RJ Jr, Alvarez RD, Armstrong DK, et al. Ovarian cancer, version 2.2013. J Natl Compr Canc Netw 2013;11:1199-1209.

34. Deyo RA, Cherkin DC, Ciol MA. Adapting a clinical comorbidity index for use with ICD-9-CM administrative databases. J Clin Epidemiol 1992; 45:613-619.

35. Lichtensztajn DY, Giddings BM, Morris CR, et al. Comorbidity index in central cancer registries: the value of hospital discharge data. Clin Epidemiol 2017;9:601-609.

36. Yost $\mathrm{K}$, Perkins $\mathrm{C}$, Cohen $\mathrm{R}$, et al. Socioeconomic status and breast cance incidence in California for different race/ethnic groups. Cancer Causes Control 2001;12:703-711.

37. Yang J, Schupp CW, Harrati A, et al. Developing an Area-based Socioeconomic Measure From American Community Survey Data. Fremont, CA: Cancer Prevention Institute of California; 2014.

38. Hastie T, Tibshirani R. Generalized Additive Models. Boca Raton, FL: Chapman \& Hall/CRC Press; 1990.

39. Webster T, Vieira V, Weinberg J, et al. Method for mapping populationbased case-control studies: an application using generalized additive models. Int J Health Geogr 2006;5:26. 
40. Erickson BK, Martin JY, Shah MM, et al. Reasons for failure to deliver National Comprehensive Cancer Network (NCCN)-adherent care in the treatment of epithelial ovarian cancer at an NCCN cancer center. Gynecol Oncol 2014;133:142-146.

41. Visser BC, Ma Y, Zak Y, et al. Failure to comply with NCCN guidelines for the management of pancreatic cancer compromises outcomes. HPB 2012;14:539-547.

42. Pfaendler KS, Chang J, Ziogas A, et al. Disparities in adherence to National Comprehensive Cancer Network treatment guidelines and survival for stage IB-IIA cervical cancer in California. Obstet Gynecol 2018;131: 899-908.

43. Boulos DN, Ghali RR, Ibrahim EM, et al. An eight-year snapshot of geospatial cancer research (2002-2009): clinico-epidemiological and methodological findings and trends. Med Oncol 2011;28: 1145-1162.

44. Reames BN, Ghaferi AA, Birkmeyer JD, et al. Hospital volume and operative mortality in the modern era. Ann Surg 2014;260:244-251.

45. Barrington DA, Dilley SE, Landers EE, et al. Distance from a comprehensive cancer center: a proxy for poor cervical cancer outcomes? Gynecol Oncol 2016;143:617-621.
46. Temkin SM, Fleming SA, Amrane S, et al. Geographic disparities amongst patients with gynecologic malignancies at an urban $\mathrm{NCl}$-designated cancer center. Gynecol Oncol 2015;137:497-502.

47. Guagliardo MF. Spatial accessibility of primary care: concepts, methods and challenges. Int J Health Geogr 2004;3:3

48. Shalowitz DI, Nivasch E, Burger RA, et al. Are patients willing to travel for better ovarian cancer care? Gynecol Oncol 2018;148:42-48.

49. Jindal M, Zheng C, Quadri HS, et al. Why do long-distance travelers have improved pancreatectomy outcomes? J Am Coll Surg 2017;225: 216-225.

50. Bristow RE, Palis BE, Chi DS, et al. The National Cancer Database report on advanced-stage epithelial ovarian cancer: impact of hospital surgical case volume on overall survival and surgical treatment paradigm. Gynecol Oncol 2010;118:262-267.

51. Jones AP, Haynes R, Sauerzapf V, et al. Travel time to hospital and treatment for breast, colon, rectum, lung, ovary and prostate cancer. Eur J Cancer 2008:44:992-999.

52. Goff BA, Matthews BJ, Larson EH, et al. Predictors of comprehensive surgical treatment in patients with ovarian cancer. Cancer 2007;109: 2031-2042 